\title{
A história da arte afro-brasileira como a história das exposiçōes de arte afro-brasileira
}

Claudinei Roberto da Silva nasceu em São Paulo em 1963, professor licenciado em Educação Artística pelo Departamento de Artes da USP, artista visual, e curador. Algumas curadorias: Sidney Amaral "O Banzo, o amor e a Cozinha" no museu Afro Brasil e a série "PretAtitude: insurgência, emergência e afirmação na arte afro-brasileira contemporânea" que visitou 5 unidades do Sesc SP. Coordenou entre outros, o núcleo educativo do museu Afro Brasil. <claudineiroberto20@gmail.com> ORCID: 0000-0002-7589-1560
Resumo Os protestos detonados pelo assassinato do afro americano George Floyd denunciam uma vez mais o racismo estrutural que caracteriza as sociedades ocidentais de todos os quadrantes, a violência que o atingiu foi promovida pelo Estado e é a mesma que aniquila cotidianamente nas periferias de todo mundo a vida de negras e negros, notadamente dos mais jovens, e confirma que a desigualdade é marca indelével não só das sociedades submetidas ao jugo colonialista mas também daquelas que o promovem. Isso vem sugerindo, ou antes, exigindo a construção de novas estratégias pedagógicas e protocolos éticos que tornem possível consolidar e tornar visíveis narrativas divergentes que contemplem a produção simbólica dos grupos historicamente excluídos para benefício de cenários sociais mais democráticos e plurais. É, portanto, central o papel que as artes exercem na construção de imaginários anti e/ou não racistas e anticoloniais o que torna incontornável a construção e difusão de uma história que contemple essa opção.

Palavras chave Colonialismo, História, Circulação/Arte, Racismo. 


\title{
The history of Afro-Brazilian art as the history of Afro-Brazilian art exhibitions
}

\begin{abstract}
The protests triggered by the murder of the African American George Floyd once again denounce the structural racism that characterizes Western societies from all quarters, the violence that hit has been promoted by the State and is the same that everyday annihilate in the suburbs of the whole world the lives of female and male blacks, notably the youngest, and confirms that inequality is an indelible mark not only of societies subjected to the colonialist yoke but also of those who promote it. This has suggested, or rather, demanded the construction of new pedagogical strategies and ethical protocols that make it possible to consolidate and make visible divergent narratives that contemplate the symbolic production of historically excluded groups for the benefit of more democratic and plural social scenarios. Therefore, the role that the arts play in the construction of anti and/or non-racist and anti-colonial imaginary is central, which making essential the construction and diffusion of a story that contemplates this option.
\end{abstract}

Keywords Colonialism, History, Circulation / Art, Racism.

\section{La historia del arte afrobrasileño como historia de las exposiciones de arte afro- brasileño}

Resumen Las protestas desencadenadas por el asesinato del afroamericano George Floyd denuncian una vez más el racismo estructural que caracteriza a las sociedades occidentales desde todos los ámbitos, la violencia que la ha afectado ha sido promovida por el Estado y es la misma que aniquila las periferias de la vida cotidiana de todos negras y negros, en especial los más jóvenes, y confirma que la desigualdad es una marca indeleble no solo de las sociedades sometidas al yugo colonialista sino también de las que lo promueven. Esto viene sugiriendo, o más bien, exigiendo la construcción de nuevas estrategias pedagógicas y protocolos éticos que permitan consolidar y visibilizar narrativas divergentes que contemplen la producción simbólica de grupos históricamente excluidos en beneficio de escenarios sociales más democráticos y plurales. Por tanto, es central el papel que ejercen las artes en la construcción de imaginarios anti y/o no racistas y anticoloniales, lo que hace imprescindible la construcción y difusión de un relato que contemple esta opción.

Palabras clave Colonialismo, Historia, Circulación/Arte, Racismo. 
Os protestos detonados pelo assassinato do afro americano George Floyd mais uma vez denunciam o racismo estrutural que caracteriza em maior ou menor grau as sociedades ocidentais, a violência que atingiu Floyd foi, como não raro acontece promovida pelo Estado; a mesma violência cotidianamente interdita e aniquila a vida de multidões de negras e negros nas periferias daqui, notadamente daqueles que dentre eles são os mais jovens e pobres, violência que confirma a desigualdade e a injustiça como à marca indelével não apenas das sociedades que foram submetidas ao jugo colonialista, mas também daquelas que promovem e exercem seu poder imperialista e neocolonial.

Isso vem sugerindo, ou antes, exigindo, a constituição de novas estratégias pedagógicas e inéditos compromissos éticos que ao confrontar o racismo torne possível a circulação de narrativas divergentes àquelas consagradas pela hierarquia branca e heteronormativa, e que, portanto, contemple a complexidade da produção simbólica dos grupos historicamente excluídos para benefício e avanço de cenários sociais mais profundamente democráticos e mais agudamente comprometidos com a diversidade. É central, desse modo, o papel exercido pelas artes na elaboração de imaginários negros, anti e não racistas, anticolonialistas e descolonizados, o que tornará incontornável a construção e difusão de uma história alternativa (inclusive de arte) que contemple essa opção pluralista e descentralizante.

As disputas em torno das matérias que pretendem definir conceitos sobre o que seria o partido estético consagrado nas manifestações artísticas afro-brasileiras ou afrodiaspóricas são relativamente recentes. Essas disputas reverberam às vezes uma ideologia que procura naturalizar uma suposta inferioridade dos negros; ideologia já observada entre os iluministas europeus que manipulavam a filosofia e a ciência no sentido de afirmar a supremacia do homem branco e europeu sobre todos os demais, essa tese é considerada na obra "A invenção do ser negro - Um percurso das idéias que naturalizaram a inferioridade dos negros" da professora e Doutora Gislene Aparecida dos Santos. Embora o protagonismo dxs negrxs na luta por sua emancipação seja antigo de séculos, como, aliás, demonstra o cientista social e jornalista Clóvis Moura em seu clássico de 1959 "Rebeliões da Senzala - Quilombos, insurreições, guerrilhas" esse protagonismo só recentemente tem sido reconhecido e administrado no meio social e acadêmico e isto graças, mais uma vez, a mobilização das parcelas organizadas da própria comunidade negra brasileira e da sensibilidade antirracista e humanista de uma porção, infelizmente ainda pequena, da coletividade branca.

Essas jornadas de luta que espelham a busca por emancipação e afirmação dxs negrxs do Brasil e de fora dele dizem respeito à sua paulatina inserção na sociedade como protagonistas de sua história, pois quando escravizados eram desumanizados e uma vez libertos transformam-se em massa excluída a quem direitos elementares que mesmo sendo escassos naquele período da história lhes foram negados. Existe, desse modo, um 
paralelo entre a luta políticas por direitos civis, do combate ao racismo e o surgimento de uma história de arte que inclua na sua dinâmica aspectos da civilização africano-brasileira.

A ausência de tradição e desconhecimento de autorias tem sido alegadas como argumentos validos para desqualificação daqueles que pretendem atribuir axs negrxs brasileiros uma história qualquer de arte, esse argumento está mais ou menos embasado numa concepção eurocêntrica de história e desconsidera por isso mesmo as particularidades de manifestações culturais de outros centros, que a propósito são vistos como subalternos àquela matriz europeia.

Aqui vale mencionar o historiador francês Jacques Le Goff que afirma:

\footnotetext{
"Faço notar também que a reflexão histórica se aplica hoje a ausência de documentos, aos silêncios da história. Michel de Certeau analisou com sutileza os "desvios" do historiador para as "zonas silenciosas", das quais dá como exemplo "a feitiçaria, a loucura, a festa, a literatura popular, o mundo esquecido do camponês, a Occitânia etc." [1974, p.27]. Falar dos silêncios da historiografia tradicional não basta; penso que é preciso ir mais longe: questionar a documentação histórica sobre as lacunas, interrogar-se sobre os esquecimentos, os hiatos, os espaços em branco da história. Devemos fazer o inventário dos arquivos do silêncio e fazer a história a partir dos documentos e da ausência de documentos" (2016, p.107).
}

No Brasil a controversa eliminação de documentos que se referissem à escravidão foi ordenada pelo jurista e político Rui Barbosa em 1890 (LACOMBE; SILVA; BARBOSA, 1988), e a destruição e captura de objetos de culto religioso, adereços e instrumentos musicais utilizados por negrxs em suas práticas religiosas ou recreativas foram rotinas corriqueiras das policias do Estado até pelo menos a primeira metade do século XX, essa prática continua pela ação de milícias neopentecostais. Talvez exista nisso certo paralelo com o inqualificável incêndio que na noite do dia 02 de setembro de 2018 devastou no Rio de Janeiro o Museu Nacional, destruindo parte inestimável do acervo daquela instituição, o acontecimento denuncia a histórica insensibilidade do Estado nas questões que afetam à preservação da memória nacional em seus múltiplos aspectos.

Apesar dos inúmeros percalços que dificultam sua aplicação a Lei número 10632/12 que confirma a obrigatoriedade do ensino da história da África e dos afrodescendentes do Brasil, a mesma provou-se um avanço no processo de amadurecimento da democracia no país, concomitante a ela está à adesão das instituições de ensino á políticas inclusão social via ampliação do acesso à educação superior por meio das cotas raciais. Tentativas de contestar e solapar essas conquistas ainda estão em curso afinal, contrariar a necessidade de políticass de reparação está em acordo com o racismo estrutural que não pode mesmo admiti-las. Não obstante, esse acesso ao ensino superior que permite, entre outras coisas, uma maior amplitude dos horizontes intelectuais á própria academia, tem também a capacida- 
de de promover uma maior inserção dxs negrxs no mercado de trabalho em setores geralmente relegados ao elemento branco, tal inserção, porém, não redime o fosso social criado pelo racismo, já que trabalhadorxs negrxs recebem remuneração sensivelmente menor que aquela recebida por um trabalhador branco que ocupe função similar a sua. Desse modo o ingresso do consumidor negro ao universo do circuito da arte e do colecionismo fica bastante comprometido e a discriminação se prova um elemento também pernicioso à circulação da obra pela via do seu consumo por outros grupos sociais além daqueles já estabelecidos.

As efemérides de caráter celebratório associadas a movimentos sociais de vulto acabam por criar condições para os exercícios de reflexão sobre nossa história social e cultural. Foi assim em 1978, 1988 e no ano 2000. O ano de 1978, 90 anos após a Abolição e em plena vigência da ditadura cívico-militar, viu a primeira grande manifestação do "Movimento Negro Unificado" acontecer nas escadarias do Teatro Municipal de São Paulo; dez anos depois em 1988, no centenário da Abolição da Escravidão aconteceria nas dependências do MAM-SP a fundamental exposição "A Mão Afro Brasileira" organizada pelo artista e curador Emanoel Araújo. A mostra de caráter enciclopédico permanece como um marco, pois entre seus méritos está o fato ter sido proposta e organizada como um levantamento exaustivo da contribuição do afrodescendente á sociedade e cultura brasileira, proposta e organizada, repetimos, por um curador e artista negro. No ano 2000 celebravam-se os 500 anos de "achamento" do Brasil (sendo habitado o território já pertencia a vários outros grupos humanos, já havia, portanto, sido "descoberto") a ocasião deu ensejo para uma série de grandes exposições acontecidas principalmente em São Paulo e reunidas sob o título de "Mostra do Redescobrimento", entre essas mostras estava a também enciclopédica "Negro de Corpo e Alma", novamente organizada por Emanoel Araujo. Estas e outras exposições menores, mas com o mesmo caráter, precederam a criação do Museu Afro Brasil em 2004.

Não é ocioso confirmar a importância de um museu que, fato relevante, está situado na capital do maior Estado da Federação dedicando-se à história, cultura e arte de uma parcela da população discriminada, precarizada e geralmente silenciada, desse modo o museu configura-se também como acontecimento ético ao salvaguardar uma produção de objetos, artefatos e obras que vão de documentos relativos ao período escravagista como cartas de alforria, recibos de venda e compra de escravizados, até artefatos de culto religioso, e claro objetos de arte que contemplam uma história que percorre o período Colonial, passa pela Academia no século XIX, Modernismo e contemporâneos. As exposições que considerando a arte e a cultura afro-brasileiras precederam ou sucederam a criação do museu Afro Brasil quase sempre acompanharam o duro amadurecimento das instituições democráticas nacionais e do avanço dos direitos civis da população, mostras que às vezes são um espelho da sociedade que contemplada em seus múltiplos aspectos. 
A história da arte afro-brasileira como a história das exposições de arte afro-brasileira

\section{Referências}

LACOMBE, Américo Jacobina; SILVA, Eduardo; BARBOSA, Francisco de Assis. Rui Barbosa e a queima dos arquivos. Rio de Janeiro: Fundação Casa de Rui Barbosa, 1988.

LE GOFF, Jacques. História e Memória. 7. ed. Campinas: Unicamp, 2016.

MOURA, Clóvis. Rebeliões da senzala: quilombos, insurreições, guerrilhas. 5. ed. São Paulo: Anita Garibaldi/Fundação Maurício Grabois, 2014. 243 p.

SANTOS, Gislene Aparecida dos. A invenção do ser negro: um percurso das idéias que naturalizaram a inferioridade dos negros. Rio de Janeiro/São Paulo: Educ/Fapesp/Pallas, 2002.176 p. 